\title{
A note on price-volume dynamics in an emerging stock market
}

\author{
Erdem Başcı ${ }^{a}$, Süheyla Özyıldırım ${ }^{a}$, Kürşat Aydoğan ${ }^{\text {b, * }}$ \\ ${ }^{a}$ Department of Economics, Bilkent University, 06533 Bilkent, Ankara, Turkey \\ ${ }^{\mathrm{b}}$ Faculty of Business Administration, Bilkent University, 06533 Bilkent, Ankara, Turkey
}

Received 1 February 1993; accepted 1 October 1994

\begin{abstract}
We present a continuum economy with risk neutral agents having heterogeneous expectations and restricted short sales. A stochastic version of the model is also formulated and the resulting time series behavior of the price and volume series under a specific money supply process derived. The implications of the model are tested in the emerging Turkish stock market where institutional arrangements comply with the restrictions of the model. The results indicate that, as predicted by the model, price levels and trading volume are cointegrated. The error correction models are also estimated and found to be significant in most cases.
\end{abstract}

JEL classification: $\mathrm{G} 14 ; \mathrm{G} 15 ; \mathrm{C} 52$

Keywords: Trading volume; Cointegration; Error correction models; Heterogeneous expectations; Emerging market

\section{Introduction}

Despite the persistent belief among stock market traders about the existence of a relationship between price changes and the volume of transactions, the empirical evidence on that relationship is not strong. ${ }^{1}$ Various authors find some evidence

\footnotetext{
* Corresponding author. Tel.: +90-312-266-4164; fax: +90-312-266-4958; e-mail: aydogan@bil kent.edu.tr.

' A survey by Karpoff (1987) contains an excellent review of the literature on the price-volume relationship.
} 
of a positive correlation between volume and the absolute value of price changes in stock, bond and futures markets. Other studies find a positive correlation between price changes and volume in the stock market. Theoretical explanations of the price-volume phenomenon mostly depend on informational asymmetries, the speed with which information is disseminated, and the distributional properties of price change series or a combination thereof.

Explanations of the stricter version of this phenomenon, i.e. the positive relationship between the price change per se and volume, usually include some other restriction on trading, mainly in the form of a restriction on short sales. However, neither empirical evidence nor theoretical justification exist for an association between price levels and transaction volume.

The purpose of this paper is to present a model to explain the existence of a relationship between price levels and volume, and to provide empirical evidence in support of the implications of this model. The basic features of the model are consistent with the characteristics of an emerging market, where reliability and availability of information on fundamental factors are questionable. To this end a framework for an economy with risk neutral agents having heterogeneous expectations and restricted short sales is developed. A stochastic version of the model is formulated and the resulting time series behavior of price and volume series under a specific money supply process derived. The implications of the model are tested on the Turkish stock market, where institutional arrangements comply with the restrictions of the model. The results indicate that, as predicted by the model, price levels and trading volume are cointegrated. The error correction models are also estimated and found to be significant in most cases.

The repercussions of these results on the efficiency of the market are worth further discussion. The Granger Representation Theorem (Engle and Granger, 1987) states that if two variables are cointegrated, they have an error correction representation. In that case it is possible to forecast at least one variable by using the past values of both series. But efficient markets require that prices reflect all available information, thus the lagged values of any variable should not enhance forecasting ability. Our finding would definitely raise serious concerns over the efficiency of the Istanbul Securities Exchange (ISE), since it seems possible that for some stocks future price changes can be can be forecast by the use of current price and trading volume.

The general equilibrium formulation of the capital asset pricing model (CAPM) developed by Sharpe (1964), Lintner (1965) and Mossin (1965) is easily made possible by the assumption of identical agents, see e.g. Lucas (1978). Assuming all individuals to be identical may not be reasonable either on theoretical or empirical grounds. However, letting agents differ in either beliefs, expectations, attitudes towards risk or asset ownership leads to some theoretical difficulties. Sharpe (1991) reflects on a case where only attitudes towards risk are different. Grossman and Stiglitz (1980) consider the case where there is asymmetric information among agents but the market price conveys all the information to the less informed 
agents. Blough (1987) argues that if differences are in opinion as well as in information, their results do not follow.

In this note, we allow agents to have differing opinions on the value of the stock in question. They are indifferent to what others think and hence their valuation is not affected by market price. In an emerging market, information on fundamentals is neither reliable nor available to all traders. Standards for financial statements are loose, and they are not strictly audited. Announcement of key facts about companies and the economy with respect to timing and content are not well organized, leaving much room for speculation, rumors or apathy. Given this excessive noise in information, market price may not signal the fundamentals, and subjective valuations of traders would differ from market prices. The resulting differences in opinion are an important reason why trade takes place. In such a case, it is first shown that heterogeneity of expectations may lead to a much deeper problem. The problem is the non-existence of an equilibrium price-allocation pair when there are no restrictions on borrowing and lending. If, however, there are restrictions on short selling, then equilibrium exists.

The paper is organized as follows. In Section 2, a framework to investigate such an economy is introduced, a stochastic version of the model is developed and the resulting time series behavior of price and volume series under a specific money supply process is derived. The implications of the model for the Turkish case are tested in Section 3. The results of the empirical findings and conclusions are summarized in the final section.

\section{The model}

There are $n+1$ assets in the economy. One of them, money, is storable but has zero yield. The remaining $n$ assets are common stocks of $n$ different companies, which are storable and yield dividend income each year. The index set of agents is a continuum, say $I=[0,1] .{ }^{2}$ The agents are risk neutral, in the sense that they only care about the expected present value of the asset that they hold. They are indifferent with regard to moments larger than the first of their subjective probability distributions.

In such a case, all the assets are perfect substitutes for any agent $i$. Also assuming that any asset has a positive value at any time for any agent, the rates of substitution will be given by a fixed vector $V_{i} \in \mathscr{R}_{++}^{n}$ of subjective money values invariant to the portfolio held.

Now a natural question to ask relates to the existence of equilibrium in such an economy. In the context of $m$ identical agents, the simplest would be a case

\footnotetext{
${ }^{2}$ The set of agents represents potentially active traders. The existence of passive/static portfolio investors who trade very infrequently would be irrelevant as far as the results are concerned.
} 
considered by Lucas (1978). If all the subjective valuation vectors were the same, i.e. homogeneous expectations, and all the rates of time preferences were the same, then $V_{i}=V$ would hold for all $i$, and the equilibrium price vector would equal $V$, and each agent would be holding one $m$ th of each asset.

In this paper, we will consider the case where the relative subjective values of the $n$ assets are identical among agents, but there is diverse opinion on the nominal (money) prices of the risky assets. Such a case boils down to the case of a two-asset economy, one asset being money and the other a portfolio of risky assets, which will be called stock from now on. Denoting the market price of stock by $p \in \mathscr{R}$, and the subjective value ${ }^{3}$ of stock for agent $i$ by $v_{i} \in \mathscr{R}_{++}$, the decision of the agent will be given by

- if $p>v_{i}$, sell as much stock as possible,

- if $p<v_{i}$, buy as much stock as possible, and

- if $p=v_{i}$, indifference between buying, selling or not trading.

As is well known, if borrowing money or short-selling stock were possible there would be no equilibrium. The reason is that at any price, there would be some agents with infinite demand for stock or money. Here we consider the case where borrowing money and short-selling stock is not possible. In that case, standard existence proofs available in the literature (e.g. Aumann, 1966) can be applied to show that competitive equilibrium exists, regardless of diversity of opinion.

The equilibrium price is determined in a way to equate supply and demand for stocks. Supply comes from the owners of stock who attach a lower value to the stock and demand comes from the owners of money who attach a higher value. Due to the restrictions on speculative borrowing, the level of demand by each agent is restricted by the amount of money he holds. Therefore an economy-wide increase in the stock of money, for instance, will lead to a higher demand and push the price up. In general, the quantity traded will also be higher under an economy-wide increase in money because at a higher equilibrium price, there will be more sell orders. Hence a ceteris paribus change in money will effect prices and volume in the same direction. This is a possible explanation for the observation that price and volume tend to move together.

For trade to take place in each period, the subjective valuations of the agents have to change over time. To see this, imagine that the valuation of each agent was fixed in time. Then after the first clearing of the market, almost all the money holders would evaluate the stock lower than all the stockholders. Hence trading volume would drop to zero and stay there after the first trading period.

To generate trade at each time in the context of our model, some change in the valuation of any given agent has to take place between the closing and reopening

\footnotetext{
${ }^{3}$ The subjective value $v: l \rightarrow \mathscr{R}_{++}$is assumed to be a measurable function on $I$.
} 
of the market. But for economists, who can observe only the trading volume and price signals, it is almost impossible to keep track of such changes at the individual level. Hence we proceed by introducing some stochastic elements into our model which will stand for the unobservable variables.

Suppose that there are three kinds of news that arrive after each trade. The first kind, true news is such that it can be justified by changes in a rational valuation formula based on available information on the fundamentals related to the common stock. The second kind, rumors, are totally temporary but they effect the valuation of all agents in the same way. The third kind, dreams, ${ }^{4}$ are signals that effect individual valuations in an independent way in time and across agents.

We will denote the fundamental value, which fluctuates only due to true news, by $f_{1}$. However, due to rumors and dreams agents will not be exactly using this fundamental value. Both money and stock will be assumed to be uniformly distributed around $f_{t}$ at each time $t$ before trading takes place (Fig. 1). More specifically, in such a case $m(M, v)$ and $s(A, v)$ will be written as

$$
\begin{aligned}
& m(M, v)= \begin{cases}0, & v<f-\sigma+\epsilon, \\
\frac{M}{2 \sigma}, & f-\sigma+\epsilon \leq v \leq f+\sigma+\epsilon, \\
0, & v>f+\sigma+\epsilon,\end{cases} \\
& s(A, v)= \begin{cases}0, & v<f-\sigma+\varepsilon, \\
\frac{A}{2 \sigma}, & f-\sigma+\varepsilon \leq v \leq f+\sigma+\varepsilon, \\
0, & v>f+\sigma+\varepsilon,\end{cases}
\end{aligned}
$$

where $M$ and $A$ are the total quantities of money and stock in the economy, $\sigma$ a positive dispersion parameter, $\epsilon$ and $\varepsilon$, which stand for rumors, are finite variance random variables and $f$ is the fundamental value of the stock. ${ }^{5}$

As seen in Fig. 1, the rumors affecting money holders and stock holders are allowed to be different. In the figure, one can immediately see the supply as the lightly shaded area under the $S$ box, and the demand as the darkly shaded area under the $M$ box divided by $p$. If $p$ is the equilibrium price, then these two numbers should be equal. In such a case, the equilibrium trading volume is given by the lightly shaded area. The effect of a change in the total quantity of money, quantity of stock, fundamental value, rumors on equilibrium price and volume can

\footnotetext{
${ }_{5}^{4}$ Nightmares are a special subcategory of dreams.

${ }^{5}$ In fact, if fundamental value is given as $f$, the rumors as $\epsilon$ and $\varepsilon$ for money and stock holders, respectively, and if dreams are independent and identically uniform distributed random variables for agents with dispersion $2 \sigma$, one would expect to obtain Eqs. (1) and (2) exactly.
} 


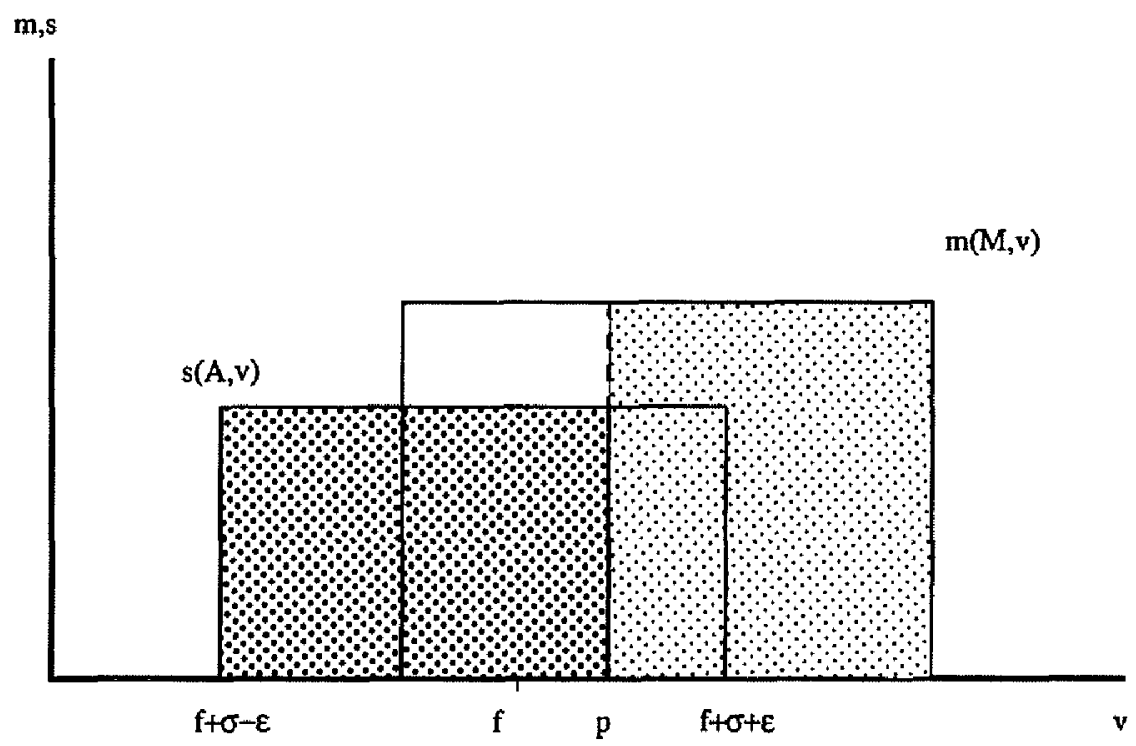

Fig. 1. The distributions of money and stocks over the value axis.

be analyzed easily using the figure. We proceed, however, with the formal analysis.

The equations giving demand and supply are

$$
\begin{aligned}
& B(M, p)=\frac{1}{p} \int_{p}^{\infty} m(M, v) \mathrm{d} v, \\
& S(A, p)=\int_{-\infty}^{p} s(A, v) \mathrm{d} v .
\end{aligned}
$$

By making use of Eqs. (3) and (4), which are integrals over the real line now, one can get for $p \in[f-\sigma+\epsilon, f+\sigma+\epsilon]$

$$
B_{t}=B\left(M_{t}, p_{t}\right)=\frac{M}{2 \sigma p_{t}}\left(f_{t}+\sigma+\epsilon_{t}-p_{t}\right)
$$

and for $p \in[f-\sigma+\varepsilon, f+\sigma+\varepsilon]$,

$$
S_{t}=S\left(A_{t}, p_{t}\right)=\frac{A}{2 \sigma}\left(p_{t}-f_{t}+\sigma+\varepsilon_{t}\right) .
$$

Since at equilibrium, $B_{t}=S_{t}=V_{t}$, supposing that $A$ and $f$ are constants in time, but $M$ is a non-stationary stochastic process with a unit root, ${ }^{6}$ we obtain the

\footnotetext{
${ }^{6}$ These assumptions are made for the Turkish market for the period investigated. The positive theoretical cointegration relation emerges under such very specific conditions. For instance, if the fundamental value has a unit root, then one would not expect to get a cointegration relation between prices and volumes. The model, however, is capable of generating very different predictions on time series behavior of prices and volume under different conditions.
} 
following cointegration relation between price and trading volume, both of which turn out to be non-stationary:

$$
V_{t}=\frac{A}{2 \sigma}\left(p_{t}-f+\sigma+\varepsilon_{t}\right)
$$

or

$$
V_{t}=\alpha+\beta p_{t}+u_{t}
$$

where $\beta=A / 2 \sigma>0$ and $u_{t}=A \varepsilon_{t} / 2 \sigma$ are stationary.

\section{Empirical evidence}

The implications of the model outlined in the previous section are tested with data from the Istanbul Securities Exchange. ${ }^{7}$ We employ a three-step procedure in the empirical tests. First, unit-root tests are undertaken to see if price and volume series are integrated of order one. Then, levels regressions are performed to test whether price and volume series are cointegrated. Finally, lagged values of the residuals from this regression are utilized in the error correction models for price and volume series.

\subsection{Data and sample characteristics}

Our data consist of weekly price and volume series on 29 individual stocks covering the 166-week period between January 8, 1988 and March 29, 1991. These are the securities which had continuous data for the period under examination. The weekly trading volumes are non-zero for all of the selected stocks. Hence we tried to reduce the possibility of stale prices as they will lead to complications in the interpretation of error correction models by magnifying the error correction coefficient of the trading volume series. ${ }^{8}$ All prices and volume are adjusted for stock dividends and rights offerings. The data is obtained from the Weekly Bulletins of the Istanbul Securities Exchange.

\footnotetext{
${ }^{7}$ ISE was established in 1986 and has experienced several advances and declines since then. Turkish Capital Market Law prohibits over-the-counter trading of listed stocks. Both the law and regulations of the exchange did not permit margin trading and short sales during the period under investigation. The exchange has imposed a $10 \%$ limit on the allowable daily price change. However, this restriction is usually relaxed during upward trends, and strictly observed in bearish markets.

${ }^{8}$ Our model allows for stale prices when rumor shocks for supply and demand move too much in opposite directions, thus causing no trade in a given period. However, we assumed this away in deriving Eq. (8), and selected our sample by excluding stocks with zero volume in any week. On the other hand, the possibility of working with prices referring to different times of the week relative to the volume still exists. This is a problem that cannot be avoided in an empirical study of a double auction market in which prices may change from trade to trade.
} 


\subsection{Empirical results}

Much of the theory of cointegration has been developed for the case where all the series are $I(1)$. In higher-order series complications may arise. Moreover, when the two series are integrated of different orders, they cannot be cointegrated. Thus we first attempt to establish the order of price and volume series through unit-root tests. Working with the natural logarithms of trading volume and prices of each one of 29 stocks, we regress the change in each series on their past level and four past changes. ${ }^{9}$ The test is a $t$-type test and relies on rejecting the null hypothesis that the series has a unit root. This requires a negative and significant test statistic on the past level of the variable. Augmented Dickey-Fuller (ADF) statistics for each price and trading volume series indicate that none are significant at $\alpha=0.10$ and some even carry the wrong sign. So we run the same models with second differences on lagged first differences and four lags of second differences. This time the ADF statistics lead to the rejection of the unit-root hypothesis, indicating that first differences are stationary. Thus there appears to be a unit root in both the price and volume series which disappears on taking first differences. All the series are integrated of order one during the period under examination.

We now turn our attention to the cointegration relation between the price level and trading volume. The following equation is estimated using OLS:

$$
\ln V_{t}=a+b \ln P_{t}+u_{t}
$$

where $V_{t}$ and $P_{t}$ represent the volume and the price level of a common stock, respectively. ${ }^{10}$ The $\log$ transformation is made to stabilize the variance of residuals, which appeared to be exponentially growing for the untransformed regression.

To test the existence of cointegration, the results of two tests are reported. These are the cointegrating regression Durbin-Watson (CRDW) statistics, and Dickey-Fuller (DF) test statistics. The critical values for these tests are obtained from Monte Carlo simulations, as reported in Engle and Granger (1987).

The results of the cointegration tests are given in Table 1. Except for one case, the volume and price levels are found to be cointegrated for all the stocks. Moreover, estimates of $b_{i}$ are positive for all cases in accordance with the model presented in Section 3. ${ }^{11}$

Since our results imply that the trading volume of an individual stock is cointegrated with its closing price, we can form a valid error correction representa-

\footnotetext{
${ }^{9}$ The test was also conducted for various other specifications. The results were found to be robust to selection of lag length for changes.

${ }^{10}$ To interpret such a regression in the context of the theory developed before, we interpret money in Section 3 as the money value of all other assets. Such a series is very likely to have a unit root.

${ }^{11}$ The results did not change when the same tests were carried out for two subperiods of equal length.
} 
Table 1

Cointegration test results. Regression of weekly log trading volume on weekend log stock price for 29 securities. (Jan 8, 1988-March 29, 1991) (166 observations).

$v_{t}=\alpha+b p_{t}+\varepsilon_{t}$

\begin{tabular}{|c|c|c|c|}
\hline Securities & $\hat{b}$ & DF & CRDW \\
\hline Akçimento & 1.024 & $-6.84^{*}$ & $0.88^{*}$ \\
\hline Bagfaş & 1.631 & -2.96 & 0.20 \\
\hline Bolu Çimento & 0.088 & $-5.97^{*}$ & $0.71^{\circ}$ \\
\hline Brisa & 1.005 & $-7.45^{*}$ & $1,00^{*}$ \\
\hline Çelik Halat & 1.373 & $-7.84^{*}$ & $1.09^{\circ}$ \\
\hline Çimsa & 0.531 & $-8.88^{*}$ & $1.25^{*}$ \\
\hline Çukurova Elek. & 1.192 & $-9.44^{*}$ & $1.41^{*}$ \\
\hline Döktaş & 0.797 & $-8.05^{*}$ & $1.13^{*}$ \\
\hline Eczacıbaşı Yat. & 0.693 & $-6.32^{*}$ & $0.78^{*}$ \\
\hline Ege Biracilık & 0.552 & $-8.56^{*}$ & 1.24 * \\
\hline Ereğli D. Ç. & 0.948 & $-5.68^{*}$ & $0.64^{\circ}$ \\
\hline Goodyear & 0.616 & $-6.97^{*}$ & $0.93^{*}$ \\
\hline Gübre Fabrikalan & 2.784 & $-5.84^{*}$ & $0.68^{\circ}$ \\
\hline Hektaş & 0.999 & $-6.19^{*}$ & $0.76^{*}$ \\
\hline İzmir D. Ç. & 1.567 & $-7.70^{*}$ & $1.05^{*}$ \\
\hline Kartonsan & 1.295 & $-7.54^{*}$ & $1.03^{\circ}$ \\
\hline Kav & 1.552 & $-4.08^{*}$ & $0.37^{* *}$ \\
\hline Koç Holding & 1.095 & $-7.34^{*}$ & $0.99^{\circ}$ \\
\hline Koç Yaturm & 1.287 & $-6.18^{*}$ & $0.76^{*}$ \\
\hline Kordsa & 1.648 & $-5.68^{*}$ & 0.63 * \\
\hline Koruma Tanm & 2.166 & $-8.49^{*}$ & $1.22^{*}$ \\
\hline Metaş & 2.271 & $-5.41^{*}$ & $0.59^{\circ}$ \\
\hline Nasaş & 1.204 & $-5.36^{*}$ & $0.62^{*}$ \\
\hline Otosan & 0.570 & -4.34 * & $0.43^{*}$ \\
\hline Pinar Süt & 1.882 & $-7.72^{*}$ & $1.05^{*}$ \\
\hline Sarkuysan & 1.456 & $-6.14^{*}$ & $0.77^{*}$ \\
\hline T. Demirdöküm & 0.849 & $-5.36^{\circ}$ & $0.60^{*}$ \\
\hline T. Şişe Cam & 0.926 & $-8.20^{*}$ & $1.17^{*}$ \\
\hline Yasaş & 0.613 & $-5.46^{*}$ & $0.62 *$ \\
\hline
\end{tabular}

* Significant at 1 percent level; critical values from Engle and Granger (1987). * * Significant at 10 percent level.

tion in order to make forecasts of either variable. The idea behind ECM is that a proportion of the disequilibrium from one period is corrected in the next period. Hence it provides a test for market efficiency. To the extent that one can forecast the price in one period with the lagged value of the error term, superior profits can be achieved. This, however, will conflict with market efficiency, which requires that information is instantaneously reflected on prices. The results of the error correction models in which weekly changes in stock prices and trading volume are regressed with the one-period lagged error term of Eq. (8) are presented in Table 2. Most of the coefficients for the error correction terms are statistically signifi- 
Table 2

Error correction models. Regression of weekly change in log stock price (volume) on previous week's cointegration error. (Jan 8, 1988-March 29, 1991) (166 observations)

\begin{tabular}{|c|c|c|c|c|c|c|}
\hline \multirow[t]{2}{*}{ Securities } & \multicolumn{3}{|c|}{ ECM for stock prices $\Delta p_{1}=\alpha+c \hat{\varepsilon}_{t-1}$} & \multicolumn{3}{|c|}{ ECM for volume $\Delta v_{1}=\alpha+c \hat{\varepsilon}_{t-1}$} \\
\hline & $\overline{R^{2}}$ & $\hat{c}$ & $t$-statistic & $R^{2}$ & $\hat{c}$ & t-statistic \\
\hline Akçimento & 0.017 & 0.0194 & $1.684^{* *}$ & 0.199 & -0.422 & $-6.364^{*}$ \\
\hline Bagfaş & 0.052 & 0.0188 & $3.003^{*}$ & 0.027 & -0.069 & $-2.105^{*}$ \\
\hline Bolu Çimento & 0.000 & -0.0004 & -0.004 & 0.178 & -0.358 & $-5.944^{*}$ \\
\hline Brisa & 0.033 & 0.0336 & $2.369^{*}$ & 0.213 & -0.470 & $-6.633^{*}$ \\
\hline Çelik Halat & 0.038 & 0.0280 & $2.547^{*}$ & 0.223 & -0.506 & $-6.848^{*}$ \\
\hline Çimsa & 0.022 & 0.0302 & $1.916^{* *}$ & 0.307 & -0.620 & $-8.494^{*}$ \\
\hline Çukurova Elek. & 0.004 & 0.0169 & 0.845 & 0.313 & -0.684 & $-8.620^{\circ}$ \\
\hline Döktas & 0.000 & 0.0016 & 0.101 & 0.261 & -0.564 & $-7.593^{*}$ \\
\hline Eczacibaşı Yat. & 0.048 & 0.0296 & $2.857^{*}$ & 0.176 & -0.372 & $-5.889^{*}$ \\
\hline Ege Biracılik & 0.006 & 0.0134 & 1.022 & 0.295 & -0.616 & $-8.261^{*}$ \\
\hline Eneğli D. Ç. & 0.087 & 0.0429 & $3.941^{*}$ & 0.122 & -0.285 & $-4.749^{*}$ \\
\hline Goodyear & 0.019 & 0.0254 & $1.796^{* *}$ & 0.211 & -0.448 & $-6.598^{*}$ \\
\hline Gübre Fab. & 0.053 & 0.0204 & $3.028^{*}$ & 0.114 & -0.286 & $-4.585^{*}$ \\
\hline Hektaş & 0.006 & 0.0087 & 0.984 & 0.169 & -0.370 & $-5.759^{*}$ \\
\hline İzmir D. Ç. & 0.058 & 0.0751 & $3.168^{*}$ & 0.179 & -0.411 & $-5.959^{*}$ \\
\hline Kartonsan & 0.026 & 0.0210 & $2.067^{*}$ & 0.224 & -0.487 & $-6.860^{*}$ \\
\hline Kav & 0.009 & 0.0011 & 1.197 & 0.067 & -0.168 & $-3.418^{*}$ \\
\hline Koç Holding & 0.088 & 0.0569 & $3.962^{*}$ & 0.203 & -0.433 & $-6.447^{*}$ \\
\hline Koç Yatınm & 0.035 & 0.0269 & $2.426^{*}$ & 0.152 & -0.344 & $-5.410^{*}$ \\
\hline Kordsa & 0.025 & 0.0217 & $2.053^{*}$ & 0.119 & -0.287 & $-4.682^{*}$ \\
\hline Koruma Tarım & 0.017 & 0.0193 & $1.672^{* *}$ & 0.250 & -0.569 & $-7.379^{*}$ \\
\hline Metaş & 0.035 & 0.0261 & $2.437^{*}$ & 0.096 & -0.240 & $-4.171^{*}$ \\
\hline Nasaş & 0.012 & 0.0129 & 1.407 & 0.126 & -0.290 & $-4.837^{*}$ \\
\hline Otosan & 0.073 & 0.3379 & $3.577^{*}$ & 0.006 & -0.018 & $-1.005^{*}$ \\
\hline Pinar Süt & 0.026 & 0.0181 & $2.067^{*}$ & 0.224 & -0.505 & $-6.854^{*}$ \\
\hline Sarkuysan & 0.041 & 0.0260 & $2.654^{*}$ & 0.144 & -0.344 & $-5.246^{*}$ \\
\hline T. Demirdöküm & 0.065 & 0.0306 & $3.358^{*}$ & 0.118 & -0.273 & $-4.670^{*}$ \\
\hline T. Şişe Cam & 0.035 & 0.0266 & $2.423^{*}$ & 0.255 & -0.562 & $-7.475^{*}$ \\
\hline Yasaş & 0.061 & 0.0280 & $3.267^{*}$ & 0.135 & -0.291 & $-5.051^{*}$ \\
\hline
\end{tabular}

*Significant at 5 percent level. ${ }^{*}$ Significant at 10 percent level.

cant, especially in the volume regressions. When the error correction term is not significant, as has been observed with some price regressions, the variable is said to be weakly exogenous, even though the two variables are cointegrated. The explanatory power of the previous period's error term on the forecast of stock price or trading volume can be inferred from the coefficient of determination, $R^{2}$, values. Low $R^{2}$ values in price regressions are quite reasonable when one considers how difficult it is to forecast the price of an individual stock. The error terms in the cointegration regressions are interpreted as rumors. ${ }^{12}$ This explains their contribution to the forecastability of future price changes. Nevertheless, the 
findings of the error correction models of individual stock prices cast serious doubt on the efficiency of the Istanbul Securities Exchange. This may stem from an unjustified diversity of opinion among traders, as described in Section 2.

\section{Summary and conclusions}

This paper has attempted to investigate the relationship between stock price levels and trading volume in a setting where certain institutional features may impose comovement of the two series. An asset pricing model which incorporates risk neutral agents with heterogeneous expectations and some institutional restrictions has been developed. The implications of the model are tested on the Istanbul Securities Exchange. The prohibition of short selling, limitations on margin trading and regulatory limits on daily price changes were some of the institutional characteristics of the ISE during the period studied. Moreover, in an inflationary economic environment, both the quantity of money and nominal values of other assets behave as random walks with drift. The increase in the supply of common stocks is a recent phenomenon, and comes in the form of infrequent jumps. Thus, the environmental settings of the model developed in Section 2 seem to be justified in the Turkish market.

In the empirical part of the paper, the existence of cointegration between price levels and trading volume has been tested. Failure of the rejection of a positive linear relation between the two series supports the predictions of the model developed earlier. The error correction models for price and volume produced significant results in most cases, raising questions about the efficiency of ISE. Unlike the traditional CAPM, the empirical tests of our model are more straightforward, given some implicit joint hypotheses on the behavior of the non-stock assets and supply of common stock.

Further work is possible on both the theoretical and empirical side. The rigorous theoretical justification for the stationary and uniform distribution of money and other assets in each trading period is lacking in this study. The same analysis would be worth carrying out in the case of an economy with a large but finite number of agents. Moreover, a similar framework can be developed for risk averse agents who trade together with risk neutrals and risk lovers under restrictions on short selling. On the empirical side, one can work directly with differ-

\footnotetext{
${ }^{12}$ As pointed out by an anonymous referee, if we allow the fundamental value in Section 2 to be stochastic, this would also contribute to the cointegration regression error term. The precise stochastic process of fundamentals would also have ramifications on the error correction model. For example, if the fundamental value has a unit root, we would not obtain the cointegration result in Eq. (7). On the other hand, when $f$ follows a mean plus white noise process, cointegration would be present, and the error correction models would include lagged price and volume changes. In this case, the exact derivation of the ECMs does not follow immediately, hence it is beyond the scope of this paper.
} 
enced data and with different assumptions on the stock supply process. Obviously, the resulting implications and their econometric tests are not going to be the same under alternative settings.

\section{Acknowledgements}

We wish to thank Patrick Asea, Stephen R. Blough, Alain D'Hoore, M. Ali Khan, Fatih Özatay, H. Nejat Seyhun, and Osman Zaim for their various comments and suggestions, and two anonymous referees of this journal for their careful reading and insightful comments. The usual disclaimer applies.

\section{References}

Aumann, R.J., 1966, Existence of competitive equilibrium in markets with a continuum of traders, Econometrica 34, 1-17.

Blough, S.R., 1987, Differences of opinion and information value of prices, Working Paper in Economics No. 201, Johns Hopkins University.

Engle, R.F. and C.W.J. Granger, 1987, Cointegration and error correction: Representation, estimation and testing, Econometrica 55, 251-276.

Grossman, S. and J.E. Stiglitz, 1980, On the impossibility of informationally efficient markets, American Economic Review 70, 393-408.

Karpoff, J.M., 1987, The relation between price changes and trading volume: A survey, Journal of Financial and Quantitative Analysis 22, 109-126.

Lintner, J., 1965, The valuation of risky assets and the selection of risky investments in stock portfolios and capital budgets, Review of Economics and Statistics 47, 13-37.

Lucas, R.E., 1978, Asset prices in an exchange economy, Econometrica 46, 1429-1445.

Mossin, J., 1965, Equilibrium in a capital asset market, Econometrica 35, 768-783.

Sharpe, W., 1964, Capital asset prices: A theory of market equilibrium under conditions of risk, Journal of Finance 19, 425-442.

Sharpe, W., 1991, Capital asset prices with and without negative holdings, Journal of Finance 46, $489-509$. 